\title{
DISPOSAL OF TYPE-II LONG-LIVED FISSION PRODUCTS INTO OUTER SPACE
}

\author{
Hiroshi Takahashi and Xinyi Chen \\ Brookhaven National Laboratory \\ Department of Advanced Technology, Building 475B \\ Upton, NY, 11973-5000
}

(516) $282-4099$

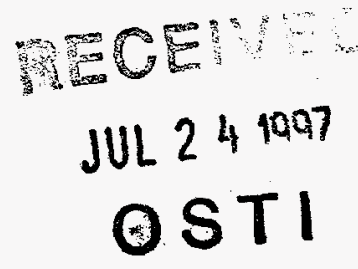

\begin{abstract}
We propose an alternative approach to dispose of long-lived fission products (LLFPs) of type-II, such as ${ }^{79} \mathrm{Se}$, ${ }^{99} \mathrm{Tc},{ }^{107} \mathrm{Pd},{ }^{126} \mathrm{Sn},{ }^{129} \mathrm{I},{ }^{135} \mathrm{Cs}$, and long-lived radioactive ${ }^{93} \mathrm{Zr}$ into outer solar space. An escape velocity from the solar system of $42 \mathrm{~km} / \mathrm{s}$ will be provided from either a parking orbit or the moon's surface using an electrostatic accelerator and by neutralizing the charged accelerated LIFPs ions. LLFP ions must be neutralized to avoid their being trapped in earth and solar magnetic fields; almost $100 \%$ neutralization can be achieved by recirculating the non-neutralized ions through a magnetic field in the neutralizing device. This mode of disposition requires $2.2 \mathrm{~kW}$ power to eject most of the LLFPs generated by one LWR. This process is much smaller than a medium-energy proton beam power, a few tens of $\mathrm{MW}$, which would be necessary to transmute these LLFPs using spallation neutrons created by protons. Due to their low radioactivity composed of mainly beta decay and low- energy gamma-rays, the shielding needed is not excessive and can be easily accommodated.
\end{abstract}

\section{INTRODUCTION}

We have been studying the transmutation of high-level radioactive wastes (HLW), produced from nuclear reactors, into short-lived nuclei (Takahashi 1980, Takahashi 1985, Bonnaue 1987, Takizuka 1990, Bowman 1992, and Takahashi 1992). The amount of LLFPs produced by a LWR per year, together with ${ }^{93} \mathrm{Zr}$ which is produced from fuel cladding material is not small, and their transmutation by neutron capture requires a substantial number of neutrons created by a nuclear reactor or spallation neutrons generated by injecting medium-energy protons of 800 $\mathrm{MeV}-3 \mathrm{GeV}$ into a heavy nuclei target, such as $\mathrm{Pb}$. The total electric energy that would be used for transmuting the LLFP produced yearly from a light-water reactor is about a few tens of MW; this would result in an increase in the cost of electricity of a few tens of percent.

The National Aeronautical and Space Administration (NASA) and Russian bave studied (NASA 1997, Egorov 1991, and Takahashi 1992) the alternative possibility of disposing of HLW using the space rocket. After launching the HLWs into parking orbit with the space shuttle, further disposition into higher earth orbit or into a near-earth solar orbit were evaluated. Both dispositions do not require a large propulsion energy because the required increment of velocity, $\Delta V$, to launch the HLW into high earth orbit is $4.11 \mathrm{~km} / \mathrm{s}$, and the velocity increment to escape earth orbit is approximately $3.23 \mathrm{~km} / \mathrm{s}$; the corresponding mass ratios (MRs) of (mass of payload + mass of fuel $) /($ mass of payload $)=\exp \left(\Delta \mathrm{V}_{\text {payload }} / V_{\text {jet exhaust }}\right)$ for these launchings are 2.65 and 2.15 , respectively, even with a chemical fuel which produces $V_{\text {jet exhaust }}=g_{e} I_{s p}=9.8\left(\mathrm{~m} / \mathrm{s}^{2}\right) \times 430 \mathrm{~s}=4.214 \mathrm{~km} / \mathrm{s}$.

However, there are several disadvantages in those methods of disposal: future planetary spacecraft would regularly penetrate this orbit belt; there is no assurance that the waste package would not encounter earth after a few thousand years; and the isolation of HLW in outer space using a rocket might disturb astronomical observations because it would be a local source of radiation.

The disposition of the HLW into an orbit escaping the solar system is ideal but requires a rocket velocity with more than $\sqrt{2} \times$ earth circular velocity $(E C)\left(V_{E C}=29.75 \mathrm{~km} / \mathrm{s}\right)=1.4142 \times 29.75 \mathrm{~km} / \mathrm{s}=42.07 \mathrm{~km} / \mathrm{s}$ to carry the HLW uniformly into the outer solar system. Furthermore, the MR becomes very high, up to 21883, when a chemical rocket is used. By using the earth's circular velocity, HLW can be disposed into the outer solar system, but uniform into the earth orbit plane; then, the velocity increment $\Delta V$ becomes $V_{E C}(\sqrt{2}-1)=29.75 \times 0.4142=$

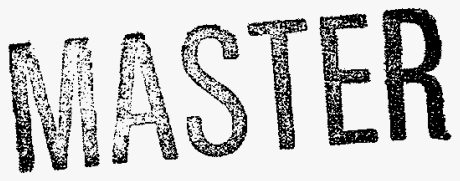




\section{DISCLAMIER}

Portions of this document may be illegible in electronic image produets. Images are produced from the best available original document. 
$12.32 \mathrm{~km} / \mathrm{s}$, and the MR can be reduced to $\exp (12.32 / 4.214=2.924)=18.618$. Nevertheless, these alternatives require enormous energy for disposing of the HLW unless a nuclear propulsion rocket can be developed which has 2 large $I_{s p}=1000 \mathrm{~s}$, or $6000 \mathrm{~s}$ for a solid-core nuclear fuel or gaseous-core nuclear fuel.

\section{DISPOSITION OF LLFP USING AN ACCELERATOR}

In a previous paper (Takahashi 1995), we proposed disposing of the type-II LLFPs by using an accelerator, instead of a rocket, to generate an escape velocity. This method would reduce substantially the energy needed for their disposal.

Type-II LLFPs are ${ }^{79} \mathrm{Se},{ }^{99} \mathrm{Tc},{ }^{107} \mathrm{Pd},{ }^{126} \mathrm{Sn},{ }^{129} \mathrm{~T},{ }^{135} \mathrm{Cs}$, and long-lived radioactive ${ }^{93} \mathrm{Zr}$ with balf-lives of more than 65,000 years; however, their radioactivity and heat generation is not as high as the LLFPs of ${ }^{90} \mathrm{Sr}$ and ${ }^{137} \mathrm{Cs}$ (type-I) whose half-lives are about 30 years. Thus, the shielding of and the system for removing heat from such LLFP packages need not be very heavy and cumbersome, and so handling the package is easier. Table 1 shows the radioactivity and the decay products of the LLFPs and ${ }^{93} \mathrm{Zr}$ generated by a standard LWR per year.

Table 1. Radioactivity and Decay Products of LLFPs, and ${ }^{93} \mathrm{Zr}$ Generated by Standard LWR Per Year.

\begin{tabular}{c|c|c|c|c|c}
\hline Isotope & Decay & $\begin{array}{c}\text { Half life } \\
\text { in year (units) }\end{array}$ & $\begin{array}{c}\text { Radiation } \\
\text { Source (Curie) }\end{array}$ & $\begin{array}{c}\text { Decayed } \\
\text { Product }\end{array}$ & $\begin{array}{c}\text { Qbeta- } \\
\text { (MeV) }\end{array}$ \\
\hline${ }^{79} \mathrm{Se}$ & beta & $6.5 \mathrm{E} 4 \mathrm{a}$ & 13.75 & ${ }^{79} \mathrm{Br}$ (stable) & 0.16 \\
\hline${ }^{93} \mathrm{Zr}$ & beta & $1.6 \mathrm{E} 6 \mathrm{a}$ & 61.39 & ${ }^{93} \mathrm{Nb}$ (stable) & 0.06 \\
\hline${ }^{99} \mathrm{Tc}$ & beta & $2.13 \mathrm{ESa}$ & 433.6 & ${ }^{99} \mathrm{Ru}$ (stable) & 0.2936 \\
\hline${ }^{107} \mathrm{Pd}$ & beta & $6.5 \mathrm{E} 6 \mathrm{a}$ & 3.73 & ${ }^{107} \mathrm{Ag}$ (stable) & 0.0331 \\
\hline${ }^{129} \mathrm{I}$ & beta & $1.57 \mathrm{E7a}$ & 1.03 & ${ }^{129} \mathrm{Xe}$ (stable) & 0.192 \\
\hline${ }^{135} \mathrm{Cs}$ & beta & $2.3 \mathrm{E} 6 \mathrm{a}$ & 8.83 & ${ }^{135} \mathrm{Ba}$ (stable) & 0.21 \\
\hline
\end{tabular}

To disperse the LLFPs into outer solar space uniformly or into the plane of earth orbit from the parking orbit, requires, respectively, $\left(V_{E E}\right)=42.07 \mathrm{~km} / \mathrm{s}$ or $V_{E C}=12.32 \mathrm{~km} / \mathrm{s}$. Table 2 shows the molecular quantities of the LLFP elements species which are generated by $1-\mathrm{GWe}$ light-water reactor per year, and the corresponding charged current for singly charged species, and the energy required to accelerate the LLFPs elements which will be disposed uniformly in the outer solar system and in an Earth orbit plane, and the corresponding accelerator power. As shown in Table 2 the accelerating energy for each LLFP isotope requires, about $1 \mathrm{keV}$ or $0.08 \mathrm{keV}$, respectively. The power for accelerating the type-II LLFPs elements and ${ }^{93} \mathrm{Zr}$ produced by one $1-G W e$ LWR to dispose them uniformly in outer space or to place them in the earth's orbit plane are $8.5 \mathrm{~kW}$ and $0.73 \mathrm{~kW}$, respectively, as shown in the fifth and seventh columns in Table 2.

These powers are far smaller than the energy required to transmute the LLFPs by spallation neutrons, which is in the order of a few 10s of MW. However, although relatively little energy is required to accelerate the LLFPs, the charged current needed to dispose of the isotropic and elemental LLFPs ions is very high. The total current for the accelerated isotopes and elements is, respectively, about 2.2 and 8.2 Amperes.

\section{NEUTRALIZATION OF LLFP IONS}

If the charged ions were ejected into outer space, the magnetic field due to earth's and sun's magnetic dipoles might trap the charged ions so that the LLFPs ions would not be dispersed into the outer solar system. To prevent trapping, the charged ions should be neutralized. 
TABLE 2. Molecular Quantities of the LLFP Elemental Species.

\begin{tabular}{l|c|c|c|c|c|c}
\hline & \multicolumn{2}{|c|}{$\begin{array}{c}\text { Production of Element Per } \\
\text { LWR-Yr }\end{array}$} & \multicolumn{2}{c|}{$\begin{array}{c}\text { Disposing Uniformly in the } \\
\text { Outer Solar System }\end{array}$} & $\begin{array}{c}\text { Disposing Uniformly in the } \\
\text { Earth Orbit Plane of Outer } \\
\text { Solar System }\end{array}$ \\
\hline Species & Moles & $\begin{array}{c}\text { Equivalent Current } \\
\text { (Ampere) }\end{array}$ & $\begin{array}{c}\text { Accelerating } \\
\text { Energy (eV) }\end{array}$ & $\begin{array}{c}\text { Accelerator } \\
\text { Power (W) }\end{array}$ & $\begin{array}{c}\text { Accelerating } \\
\text { Energy (eV) }\end{array}$ & $\begin{array}{c}\text { Accelerator } \\
\text { Power (W) }\end{array}$ \\
\hline Se & 23.8 & 0.728 & 722.2 & 525.8 & 61.9 & 45.1 \\
\hline Zr & 1297.4 & 3.969 & 850.2 & 3374.4 & 72.9 & 289.3 \\
\hline Tc & 259.5 & 0.794 & 905.0 & 718.5 & 77.6 & 61.6 \\
\hline Pd & 427.3 & 1.307 & 978.2 & 1278.8 & 83.9 & 109.7 \\
\hline Sn & 46.0 & 0.141 & 1151.9 & 162.1 & 98.8 & 13.9 \\
\hline I & 60.5 & 0.185 & 1179.3 & 218.3 & 101.1 & 18.71 \\
\hline Cs & 588.1 & 1.80 & 1234.2 & 2220.3 & 105.8 & 190.3 \\
\hline Total & & 8.209 & & 8498.2 & & 728.6 \\
\hline
\end{tabular}

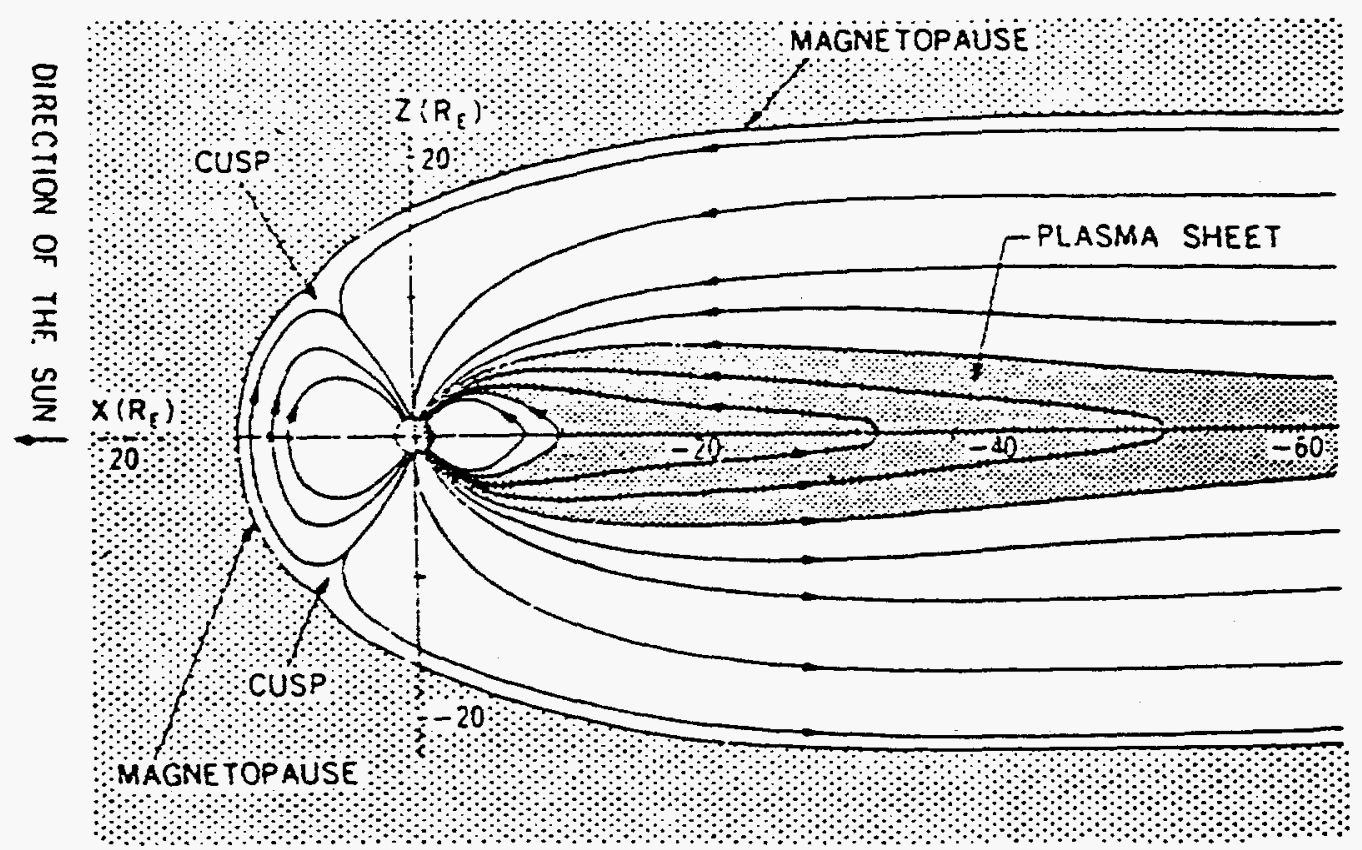

FIGURE 1. The Noon-midnight Section of Magnetosphere of the Earth. 
Figure 1 shows the magnetic field surrounding the earth (Nishida 1982). Because of the solar wind the magnetic field does not conform to a dipole configuration; rather, it is elongated outward from the direction of the sun.

The Larmor radius $\rho$ of a circular orbit of unit charge $(q=e)$ particle with momentum $P$ (Pc is in units of $e V$ ) in the magnetic field $B$ is expressed by

$$
\rho(c m)-\frac{(P c / e)}{300 * B(\text { Gauss })}
$$

where $P$ is expressed from the kinetic energy $E_{k \text { kin }}$ of nucleus with mass number $A$ (and $m=$ nucleon mass) as

$$
p c=\left(E_{k i n}^{2}+2 E_{k i n} A m c^{2}\right)^{\frac{1}{2}}
$$

For a nucleus with a mass number $\mathrm{A} \approx 100$ and an $\mathrm{E}_{\mathrm{kin}}=10 \mathrm{kev}, \mathrm{Pc}$ becomes $1.4^{*} 10^{7} \mathrm{eV}$, and $\mathrm{B} \rho=$ $1.4 * 10^{7} / 300=4.7 * 10^{4} \mathrm{G}-\mathrm{cm}$. Thus, at the earth's surface where the magnetic field is 0.3 gauss, $\rho$ becomes 1.6 $\mathrm{km}$. Since the radius is very small compared to the size of the magnetopause, once a non-neutralized LLFP fails to become neutralized, it can hairdly escape the magnetopause.

The molecular density above the upper atmosphere is expressed approximately by

$$
c(x)=c(0) e^{-\alpha x}
$$

where $x$ is altitude in units of $\mathrm{km}$, and $c(0)=3.5684^{*} 10^{19} \mathrm{~cm}^{-3}$, and $\alpha$ is $0.1479 \mathrm{~km}^{-1}$, values which are obtained from extrapolating the concentration below $120 \mathrm{~km}$ at middle latitudes (Brausseur 1986). To avoid the ionization of neutralized LLFPs from collisions with atmospheric molecules, the LLFPs should be ejected from the space shuttle at an altitude above $220 \mathrm{~km}$. The distance from earth to the magnetopause boundary in the direction opposite to the sun is more than 100 times the earth's radius; there, the density of particles decreases rapidly enough so that the LLFP elements can be ejected in this direction.

After the neutral particles pass through the magnetopause, they are affected when they are ionized only by the interplanetary magnetic field the intensity of which is about $10^{-4}$ gauss. The Larmor radius of the ionized LLFP is order of $4.8 * 10^{3} \mathrm{~km}$, which is far smaller than the distance between the earth and sun. On the outside of the magnetopause region, the proton density is in the order of $1 / \mathrm{cm}^{3}$, and the ionization cross section of a particle is less than $5 \times 10^{-15} \mathrm{~cm}^{2}$; thus, the total cross section becomes of the order of $5 \times 10^{-15} \mathrm{~cm}^{-1}$. The mean free path of $2 \times 10^{14} \mathrm{~cm}$ is comparable to the radius of the solar system which is roughly the distance between the sun and Pluto, that is, 40 times the distance between the sun and earth $(0)=40 \times 1.5 \times 10^{13} \mathrm{~cm}=6 . \times 10^{14} \mathrm{~cm}$. Therefore, the neutral beam might become ionized before escaping the solar system. However, the solar magnetic field in this region might be mingled with the galactic magnetic field and therefore, the ionized LLFPs will be transported to outer space without their becoming trapped inside the solar system. Outside the magnetopause, there is the solar wind the average velocity of which is mainly radial, and its magnitude is about $400 \mathrm{~km} / \mathrm{s}$. Its average density about 5-10 ion-electron pairs/ $\mathrm{cm}^{3}$ (Kern 1982).

Although the probability of ionizing LLFP ions by colliding with such solar-wind particles is a little higher than for collisions with interplanetary protons, since the density of solar-wind particles decreases inversely proportional to square of the distance from the sun, the effect of solar wind on the mean free path is small. However, when the sun is active so that solar flares are blasted from sun spots, the proton intensity increases more than about $10^{7}$ times above that of the regular solar wind; thus, the ejection of LLFP should be avoided when the sun is active. When LLFP is ejected in the radial direction away from the sun with solar escape velocity of $42.07 \mathrm{~km} / \mathrm{s}$, it takes about 5 years to reach to the outer edge of the solar system. 


\section{ACCELERATOR AND NEUTRALIZER}

To neutralize the accelerated LIFP elements, in our previous paper we discussed the use of a negative ion accelerator which was developed for the Tokamak fusion reactor. Although in the fusion reactor, into which the deuteron energy more than $1 \mathrm{MeV}$ is injected so that negative ions must be used, in our disposal case, the energy needed to accelerate ions, whose mass number is about 100, is only keVs for these elements; this is so small that it is not necessary to use negative ions. The low-energy positive ions can be accelerated with a positive ions accelerator which is smaller than the accelerator for negative ions. Since the accelerating energy for LLFP ions is small, this accelerator can be similar to the ion source developed for heavy-ion fusion, and it can be loaded in the cargo space of the space shuttle without difficulty.

The neutralization cross section depends on the velocity of ions; the $1 \mathrm{keV}$ ions of mass $A=100$ is almost the same as the hydrogen of $1 \mathrm{kev} / 100=10 \mathrm{eV}$. The cross section of neutralization through Cs gas is above $10^{-16}$ $\mathrm{cm}^{2}$. The positive ions are neutralized through the negatively charged gas jet such as Cs, and to get almost $100 \%$ neutralization, the non-neutralized ions are recirculated by magnet and are inserted to the ion source region as shown in Figure 2.

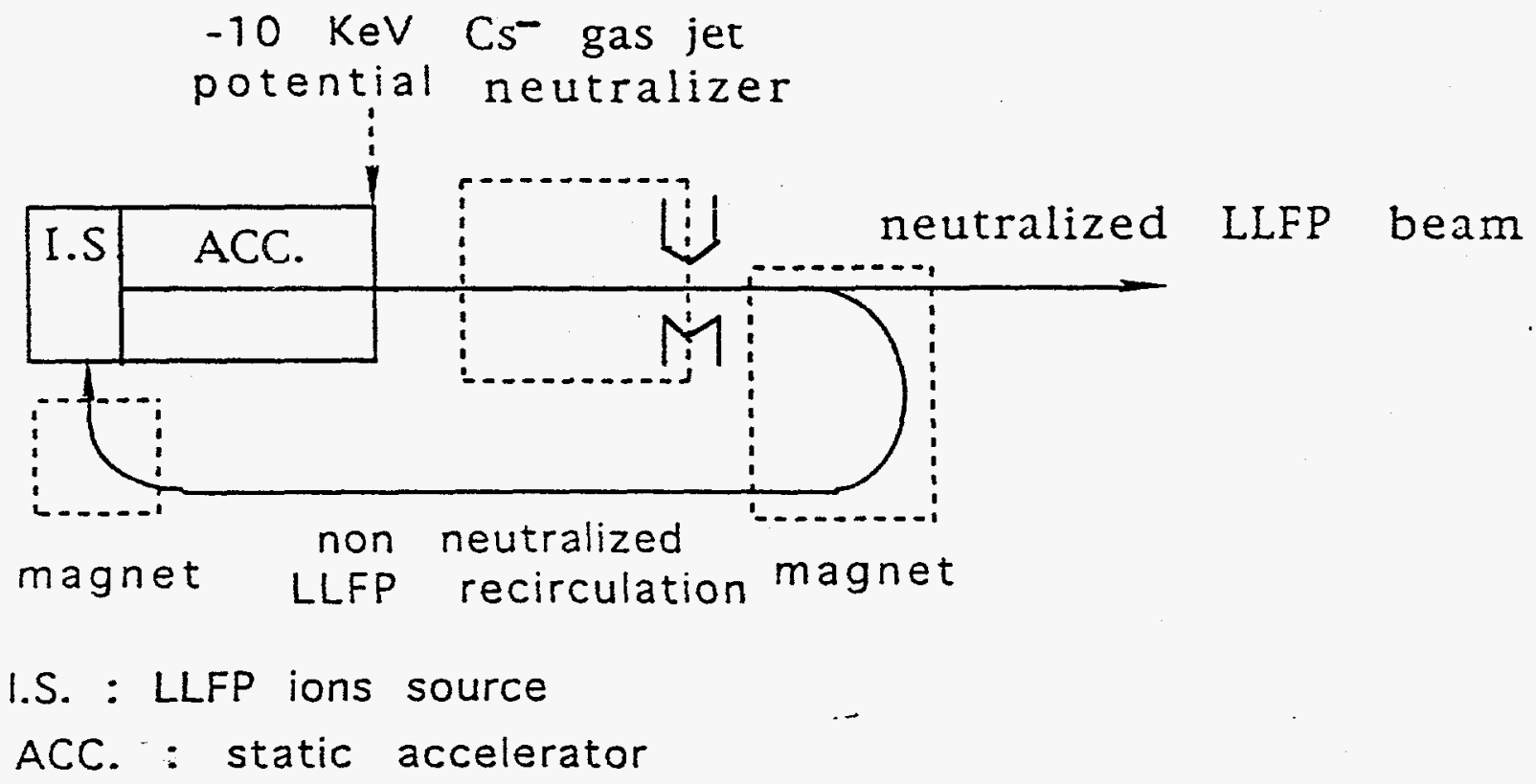

FIGURE 2. The Accelerator and Neutralizer of LLFPs.

\section{RADIATION LEVEL OF TYPE-II LLFP DISPOSED}

Since the rate of decay of these LLFPs-II is about $10^{6}$ times less than the type-I such as ${ }^{90} \mathrm{Sr}$ and ${ }^{137} \mathrm{Cs}$ which have half-lives of about 30 years, the radiation level of the type-II LLFPs is much smaller than the HLW which is loaded into the space shuttle in the NASA study as shown (Table 1).

To protect personnel and apparatus in the space shuttle from the radiation of these LLFPs, a shielding of only a few $\mathrm{cm}$ of thickness is sufficient because the decay of these LLFPs are beta emissions and the gamma rays produced after beta decay are, at moşt, $1 \mathrm{MeV}$. 
Concerning a launch failure which might contaminate the earth, some protection is needed against the spread of contamination due to rupture of the container, but the tonnage of this load is small in contrast with the case of HLWs with their heavy shielding material; thus, the possibility of rupturing the container due to impact of filling on the earth's surface is smaller than in the case of the HLW container studied by NASA. Also, a protective device such as a parachute gear could be a valuable safety feature to protect a container of type-II LLFPs.

\section{CONCLUSION}

The energy needed to dispose of type-II LLFPs or the associated elements such as ${ }^{93} \mathrm{Zr}$, into outer solar space using an electrostatic accelerator could be very much smaller than that required for disposing of HLW by launching them with a chemical rocket. The radiation level of type-II is slight, so there is no problem of heat removal which is required for type-I LLFP such as ${ }^{90} \mathrm{Sr}$ and ${ }^{137} \mathrm{Cs}$. Also, the tonnage of the loading package is small, so that the risk of aborting a misguided launching from the earth surface using a rocket is far lower.

Compared to transmuting LLFPs using neutrons generated by spallation and multiplied in a subcritical assembly, the accelerator power needed is about $10^{-3}$ less, so the approach becomes very economical.

The accelerated positively charged LLFPs can be neutralized almost perfectly by recirculating the non-neutralized LLFP using the magnetic field; furthermore, the LLFPs can escape the magnetopause without being trapped when they are launched at a high altitude of more than $220 \mathrm{~km}$ above ground level.

\section{Acknowledements}

The authors would like to express their thanks to Drs. G. Bozoki, J.G. Alessi, and Prof. S. Mikami for valuable discussions and for providing them with some of the information in this report, and also Dr. A.D. Woodhead for her editorial work. This work was performed under the auspices of the U.S. Department of Energy under Contract No. DE-AC02-76CH0O016.

\section{References}

Bonnaue, P., H. Rief, P. Mandrillon and H. Takahashi (1987) "Actinide Transmutation by Spallation in the Light of Recent Cyclotron Development," NEACRP-A-910, Session B.1.2, (European American) Reactor Physics Committee Report, Nuclear Energy Agency, Organization for Economic Co-operation and Development, Paris, France.

Bowman, C. D., E. D. Arther, et al. (1992) "Nuclear Energy Generation and Waste Transmutation Using an Accelerator-Driven Intense Thermal Neutron Source," Nucl. Inst. Meth. A320:336.

Brausseur, G. and Solomon, S. (1986) "Aeronomy of the Middle Atmosphere," D. Reidel Publishing Co. Dordrecht, 46.

Egorov, N. N., et al. (1991) "Fuel Management in the USSR and New Way to Solve the Problem," Moscow Radio-Technical Institute of the USSR Academy of Sciences, Atomic Energy Industry Radioactive Waste Handling Problem, ISBN 5-201-09424-4.

Kern, J. W. (1982) "Magnetosphere and Radiation Belts," in Magnetospheric Plasma Physics, Edited by A. Nishida, Centre for Academic Publication, D. Reidel Publishing Company, 1037.

National Aeronautic and Space Administration, Lewis Research Center (1974) "Feasibility of Space Disposal of Radioactive Waste," II- Technical Summary, NASA Report TMX-2912.

Nishida, A. (1982) "Origin of Magnetospheric Plasma, " in Magnetospheric Plasma Physics, A. Nishida, ed., Centre for Academic Publication, D. Reidel Publishing Company, 1. 
Takahashi, H., N. Mizoo and M. Steinberg (1980) Use of Linear Accelerator for Incinerating the Fission Product of 137Cs and 90Sr," Inter. Conf. on Nuclear Waste Transmutation, July 22-24. The University of Texas at Austin.

Takahashi, H. (1985) "Actinide Transmutation by the Spallation Process," presented at Workshop on the Feasibility of Research Program in Actinide Transmutation by Spallation Process, Euratom, Ispra, Varese, Italy, June 18-21.

Takahashi, H. and H. Rief (1992) "Concept of Accelerator Based Transmutation System," Proc. of the OECD Specialist Meeting on Accelerator Based Transmutation, H. U. Wenger, ed., Paul Scherrer Institute, Switzerland, March, 25-26, 2-26.

Takahashi, H. (1992) "The Use of Minor Actinides and a Small Power Proton Accelerator for Fast Reactor With a High Breeding Gain (Alternate Ways to Dispose of High Level Waste: The Merits of the Antarctic Icefield, the Moon, and Outer Space)," Proc. of the Specialist's Meeting on the Accelerator Based Transmutation PSI, Villigen, Switzerland, PSI Proc., 92-02.

Takahashi, H. and Chen, X. (1995) "Alternative Way to Dispose of High-Level Waste in Outer Space," Twelfth Symposium on Space Nuclear Power and Propulsion, AIP Conference, Proc. 324:347-354.

Takizuka, T., H. Takada, I. Kanno, T. Ogawa, T. Nishida and Y. Kaneko (1990) "A Conceptual Study of Actinide Transmutation System with Proton Accelerator," Proc. of 2 nd International Symposium in Advanced Nuclear Energy Research, Mito, JAERI, Jan. 24-26, 381.

\section{DISCLAIMER}

This report was prepared as an account of work sponsored by an agency of the United States Government. Neither the United States Government nor any agency thereof, nor any of their employees, makes any warranty, express or implied, or assumes any legal liability or responsibility for the accuracy, completeness, or usefulness of any information, apparatus, product, or process disclosed, or represents that its use would not infringe privately owned rights. Reference herein to any specific commercial product, process, or service by trade name, trademark, manufacturer, or otherwise does not necessarily constitute or imply its endorsement, recommendation, or favoring by the United States Government or any agency thereof. The views and opinions of authors expressed herein do not necessarily state or reflect those of the United States Government or any agency thereof. 